\title{
Eisen voor de jaarrekening te ontlenen aan de jurisprudentie ${ }^{1}$
}

\section{Inleiding}

De voorschriften omtrent de inrichting van jaarrekeningen van de in art. $306 \mathrm{BW} 2$ bedoelde rechtspersonen (NV, BV, Coöperatieve vereniging en onderlinge waarborgmaatschappij) zijn opgenomen in titel $6 \mathrm{BW} 2$. Bij bezwaren tegen de vastgestelde en/of goedgekeurde jaarrekening kan men zich wenden tot de ondernemingskamer $(\mathrm{OK})$ van het gerechtshof te Amsterdam. De voorschriften daaromtrent zijn eveneens in titel BW2 opgenomen.

Daar de wettelijke inrichtingsvoorschriften ten dele een algemeen karakter hebben en ook de toepassing van de wettelijke minimumvoorschriften niet altijd even duidelijk is, is de uitleg van de jaarrekeningrechter $(\mathrm{OK})$ voor de verslaggevingspraktijk (opstellers en accountants) belangrijk. Een grondige bestudering van de arresten van de OK is daarom noodzakelijk teneinde vast te stellen of bepaalde uitspraken - na eliminatie van de bijzonderheden van de individuele casus - van algemene betekenis zijn. Deze algemene betekenis is overigens ook beperkt, daar het uitsluitend gaat om de jaarrekeningen van de in artikel $306 \mathrm{BW} 2$ bedoelde rechtspersonen. Niettemin kan worden aangenomen dat de uitspraken van de OK, voor zover zij een algemeen karakter hebben, ook van invloed zullen zijn op de jaarrekeningen van andere ondernemingen.

Hierna wordt nagegaan aan de hand van een zestal onderwerpen of er algemene eisen aan de jurisprudentie van de OK zijn te ontlenen. Deze onderwerpen zijn:

- waarderings- en resultaatbepalingsgrondslagen;

- valuta-omrekeningsgrondslagen;

- stelselwijzigingen;

- deelnemingen;

- voorzieningen en

- segmentatie van omzet, kosten en resultaat.

Men dient zich wel te realiseren dat het aantal waarnemingen tot dusverre beperkt is. Ter illustratie geef $i k$ het volgende overzicht: 
* einduitspraken zonder cassatie

$\star$ arrest Hoge Raad zonder terugverwijzing

arrest Hoge Raad met terugverwijzing

einduitspraken met kracht van gewijsde

Van deze 19 uitspraken zijn er drie waarbij de OK aan een beoordeling van de materiële geschilpunten niet is toegekomen, zodat per saldo 16 arresten overblijven waarin één of meer materiële geschilpunten aan de orde kwamen.

Uitgangspunt van de beoordeling door de $\mathrm{OK}$ is dat in het algemeen uitgegaan wordt van de visie van de bevoegde organen, indien zij op aanvaardbare gronden tot die visie konden komen en de accountant die visie deelt. In dit verband is een belangwekkende constatering in de Michel Dufour-procedure dat het in een jaarrekeningprocedure niet gaat om de verantwoording van een beleid zoals dat volgens een belanghebbende had behoren te worden gevoerd, doch om de verantwoording van het beleid zoals dit in feite is gevoerd. Het gaat om de weerslag van dat beleid in de jaarrekening.

\section{Waarderings- en resultatenbepalingsgrondslagen}

Voor het inzicht dat de jaarrekening dient te geven zijn uiteenzettingen van de toegepaste grondslagen van waardering en van resultaatbepaling noodzakelijk. Deze uiteenzettingen dienen in het algemeen gescheiden te worden gegeven $\mathrm{nl}$. een uiteenzetting met betrekking tot de waarderingsgrondslagen en een uiteenzetting met betrekking tot de resultatenbepalingsgrondslagen (arrest inzake Van Gelder). Dit geldt zowel voor de enkelvoudige jaarrekening als voor de geconsolideerde jaarrekening. Wel kan men in de geconsolideerde jaarrekening volstaan met een verwijzing naar de enkelvoudige jaarrekening e.o.

De kwaliteit van de te geven uiteenzetting wordt wel beïnvloed door de aard en de omvang van de onderneming. Zo oordeelde de $\mathrm{OK}$ in de procedure Eggerding dat uit hetgeen in de jaarrekening is vermeld en toegelicht, in onderling verband gezien, Eggerding de winst gerealiseerd acht op het tijdstip van het verrichten van een dienst en dat ten laste van de winst al die kosten worden gebracht die op de omzet betrekking hebben. Het zou voor Eggerding te ver gaan om te eisen dat een verdere uiteenzetting en toelichting moet worden gegeven.

De gegeven uiteenzettingen moeten meer omvatten dan een blote vermelding (o.m. Douwe Egberts). In het gecasseerde KSH-arrest bleek dat de omschrijving 'waardering tegen benaderde vervangingswaarde' onvoldoende is. Ook een aanduiding als 'waardering tegen kostprijs' is onvoldoende: 
vermeld moet worden of het al dan niet om integrale kostprijs gaat en is van een integrale kostprijs geen sprake dan moet worden aangegeven welke kostencategorieën ontbreken. Voorts is een beknopte vermelding van de waarderingsgrondslagen van de in de kostprijs begrepen kostencategorieën noodzakelijk (gecasseerd KSH-arrest; Pakhoed 1977). Uit de procedure Michel Dufour blijkt dat de OK het van belang acht dat in de jaarrekening van de dochtermaatschappij wordt aangegeven de wijze waarop het resultaat wordt beïnvloed door de verhouding moeder- en dochtermaatschappij. Deze verplichting geldt zowel met betrekking tot de prijsstelling als met betrekking tot de financieringskosten inzake de onderlinge leningen.

Ook de aanvaardbaarheid van bepaalde stelsels is in vele procedures aan de orde geweest. Hierbij wordt duidelijk dat de OK in een aantal gevallen als element bij de beoordeling omtrent de aanvaardbaarheid de toelichting op het toegepaste stelsel een rol laat spelen. Zo oordeelde de OK in de $\mathrm{KSH}$-procedure dat een stelsel van voorraadwaardering aanvaardbaar is bij juiste toepassing en toelichting. In de Pakhoed-procedure (1978) acht de OK de door Pakhoed toegepaste waardering van onderhanden werken mits duidelijk toegelicht niet in strijd met art. 311. Enige andere voorbeelden waarbij de OK een stelsel aanvaardbaar achtte, zijn:

- waardering van zeeschepen tegen kostprijs of lagere bedrijfswaarde (Ultramarco 1975);

- het in de waardering opnemen van kosten van vermogensbeslag (Pakhoed 1978)

- het naar rato van de kouwstand verantwoorden van winst (Pakhoed 1978);

- het opnemen van een voorzichtig bepaalde winstopslag voor in opdracht van derden uitgevoerde projecten over het reeds geproduceerde deel (Ogem 1978);

- voorbereidingskosten van advertentiecampagnes toerekenen aan het jaar van voorbereiding, le advertentiekosten aan het jaar van plaatsing van de advertenties en de overige reclamekosten ten laste van het jaar waarop zij betrekking hebben (Michel Dufour);

- waardering van de voorraad boten waarin rekening wordt gehouden met het gebruikt zijn en met een zekere mate van veroudering (Michel Dufour);

- afschrijving op onroerend goed volgens de annuiteitenmethode, ingeval geen versnelde economische slijtage is te verwachten (Ogem 1978).

Uit het voorgaande kunnen als algemene eisen in ieder geval worden afgeleid:

- de stelsels moeten voldoen aan de norm van art. 311 lid 1, deze stelsels moeten goed worden toegepast en worden toegelicht;

- de uiteenzetting van de toegepaste grondslagen omvat meer dan alleen een blote vermelding;

- de uiteenzettingen van de grondslagen van waardering en resultaatbepaling dienen in het algemeen gescheiden te worden weergegeven. 


\section{Valuta-omrekeningsgrondslagen}

Er zijn geen specifieke bepalingen omtrent de behandeling van koersverschillen in de wet opgenomen. Wel bevat de komende wetgeving als voorschrift dat de gehanteerde omrekeningsgrondslagen moeten worden uiteengezet met vermelding van de verwerking van de koersverschillen.

In de jurisprudentie is deze problematiek enigszins aan de orde geweest. Inzake Ultramarco 1977 blijkt dat de betreffende onderneming als systeem heeft dat in vreemde valuta luidende activa en passiva worden omgerekend tegen ultimokoers en dat koersverschillen uit hoofde van de omrekening van het eigen vermogen van in vreemde valuta geadministreerde deelnemingen en van in vreemde valuta luidende vorderingen en schulden op lange termijn ten gunste van of ten laste van het eigen vermogen worden gebracht. De bij Ultramarco in bedrijf zijnde cruisevloot is sedert 1977 in het bezit van buitenlandse deelnemingen die de schepen in dollars administreren; de omrekening van dollars in guldens leidt aldus de OK niet tot een lagere waardering van de schepen, zoals eiser meent, maar alleen tot koersverschillen. De OK merkt hierbij op dat door eiser niet is gesteld dat de wijze van behandeling - dus de verwerking van de verschillen via het eigen vermogen - ten onrechte is geschied. Dat de verwerking van de koersverschillen zoals Ultramarco dit doet een toegelaten verwerkingswijze is blijkt uit het arrest Ogem 1978. In die procedure oordeelde de OK dat een systeem waarbij de door koerswijzigingen veroorzaakte vermogensverschillen, vastgelegd in buitenlandse deelnemingen en de in verband daarmee afgesloten leningen in vreemde valuta's, ten laste van de voorziening worden gebracht in strijd is met art. 311 , omdat het niet gaat om het treffen van voorzieningen tegen op balansdatum bestaande risico's, doch om waarderingswijzigingen. Bijboeking of afboeking van deze verschillen op de reserve is wel in overeenstemming met art. 311 (arrest inzake Ogem).

Uit het voorgaande blijkt dat in ieder geval het afboeken van valutaomrekeningsverschillen ten laste van een voorziening onjuist is en dat het verantwoorden van deze verschillen buiten de winst- en verliesrekening aanvaardbaar is. In dat geval is verwerking onder het eigen vermogen noodzakelijk. Of het verwerken via de winst- en verliesrekening een aanvaardbare gedragslijn is, kan thans nog niet worden vastgesteld.

\section{Stelselwijzigingen}

Wijzigingen in de toegepaste grondslagen, indien van wezenlijk belang, moeten worden uiteengezet, onder vermelding van de invloed op het vermogen en het resultaat. Een motiveringseis voor een stelselwijziging is naar de letter niet in de wet opgenomen. De komende wetgeving acht deze motivering wel noodzakelijk en acht stelselwijziging slechts mogelijk wegens gegronde redenen. Ook wordt expliciet in de komende wetgeving geëist dat wijziging in de indeling van de jaarrekening slechts wegens gegronde redenen mogelijk is. De redenen moeten worden uiteengezet en de verschillen moeten worden toegelicht.

Onder de geldende regels voor de jaarrekening moet in weerwil van de 
wettekst reeds thans worden aangenomen dat stelselwijzigingen alleen wegens gegronde redenen toelaatbaar zijn, en dat de redenen daarvoor eveneens vermeld moeten worden. Stelselwijzigingen zijn aan de orde geweest in de Vulcaansoordprocedure, bij het gecasseerde $\mathrm{KSH}$-arrest, in de Pakhoedprocedure, in de Sijthoffprocedure, in de Van Gelderprocedure en in de Ogemprocedure. In de Ogemprocedure heeft de OK de voorwaarden van stelselwijziging fraai verwoord. Zij merkt daarbij op dat

- mede gezien de eis van stelselmatige toepassing er gegronde redenen voor stelselwijziging moeten zijn;

- deze redenen mede ter waarborging van de stelselmatige toepassing moeten worden vermeld;

- de aanvaardbaarheid van een stelselwijziging beoordeeld dient te worden naar het inzicht dat de jaarrekening in haar geheel moet geven, mede in het licht van recent voorafgaande jaarrekeningen.

De genoemde drie redenen werden ook reeds in het gecasseerde $\mathrm{KSH}$-arrest aangetroffen. De eis van gegronde redenen kwam ook reeds in het Vulcaansoord-arrest voor. In dat laatste arrest oordeelde de OK ook dat een verandering van een één jaar toegepast systeem naar een ander systeem reeds een systeemwijziging inhoudt. In de procedure Pakhoed 1978 oordeelde de OK dat het voor het eerst in consolidatie nemen omdat een belang van $50 \%$ een $100 \%$ belang werd, geen systeemwijziging is.

Naast de zojuist genoemde voorwaarden zijn uit de jurisprudentie nog andere eisen af te leiden. Het nieuwe systeem moet eveneens aanvaardbaar zijn, het nieuwe systeem moet juist worden toegepast en het nieuwe systeem moet juist worden toegelicht. Voorts dient de invloed op het vermogen en het resultaat te worden weergegeven en dient dit op juiste wijze te geschieden.

Ongeoorloofdheid van stelselwijziging werd aangenomen bij Ogem. In afwijking van de vroegere gedragslijn werd een verlies op een deelneming ten laste van een voorziening gebracht. Ook de overgang van een systeem waarbij voor de backservice de contante waarde werd gepassiveerd, naar een systeem waarbij alleen de jaarpremie ten laste van het resultaat wordt gebracht is ongeoorloofd, tenzij de toelichting de contante waarde van de backservice vermeldt (Vulcaansoord). De overgang van een systeem waarbij over de herwaarderingsreserve latente belastingvoorzieningen in aanmerking worden genomen naar een systeem waarbij zulks niet gebeurt, keurde de $\mathrm{OK}$ in het gecasseerde $\mathrm{KSH}$-arrest $\mathrm{af}^{3}$. In de Van Gelderprocedure keurde de $\mathrm{OK}$ af het systeem om met actieve latenties uit hoofde van carry forward rekening te houden.

Geoorloofd achtte de OK een stelselwijziging bij Vulcaansoord. Deze onderneming liet een $10 \%$-afschrijving op voorraden vervallen omdat deze o.m. het karakter van een stille reserve verkreeg. De overgang van een systeem waarbij de koersverschillen t.l.v. een voorziening werden gebracht is eveneens geoorloofd (Ogem). Ook een overgang van een aanvaardbaar stelsel naar een ander aanvaardbaar stelsel is onder omstandigheden eveneens toelaatbaar $(\mathrm{KSH})$.

De geoorloofdheid van stelselwijziging betekent dat er gegronde redenen moeten zijn, dat de redenen vermeld moeten worden en dat de redenen 
juist moeten zijn. Zo werd in de procedure Vulcaansoord een toelichting als 'niet langer noodzakelijk' onvoldoende geoordeeld. In de KSHprocedure verweet de OK de betrokken onderneming dat de redenen niet vermeld waren en dat de toelichting onjuist was. In de Ogemprocedure werd terzake van de gewijzigde verwerking van koersverschillen opgegeven dat de primaire doelstelling van de voorziening waarin deze verschillen werden verwerkt in gedrang kwam. De OK achtte deze reden onjuist. Men had moeten aangeven dat het gaat om de overgang van een niet (meer) aanvaardbaar stelsel naar een aanvaardbaar stelsel.

Omtrent de voorwaarde dat een en ander in het licht van de jaarrekening in haar geheel, met inachtneming van recente voorgaande jaren moet worden gezien, oordeelde de OK dat niet kan worden volstaan met de invloed van elke stelselwijziging die op zichzelf van wezenlijk belang is, maar dat tevens de invloed van alle wijzigingen indien zij te zamen van wezenlijk belang zijn, moet worden vermeld (gecasseerd $\mathrm{KSH}$-arrest).

Wat de wijze betreft waarop de invloed van een stelselwijziging op het vermogen en het resultaat moet worden vermeld, heeft de OK opgemerkt dat het effect van de wijziging per aanvang van het boekjaar zichtbaar moet worden toegevoegd aan het eigen vermogen en dat het verschil tussen het resultaat volgens het oude en het nieuwe systeem moet worden vermeld (Vulcaansoordarrest).

\section{Deelnemingen}

Bij deelnemingen spelen vier aspecten een rol n.l.:

$a$. een kwalificatievraagstuk (wat is een deelneming);

$b$. een waarderingsvraagstuk (hoe worden deelnemingen gewaardeerd);

c. een informatievraagstuk (welke inlichtingen moeten worden verstrekt);

d. consolidatietechniek.

\section{ad a. Kwalificatieuraagstuk}

Een kwalificatievraagstuk kan onder de huidige wet alleen aan de orde komen bij kapitaalbelangen die tussen 0 en $25 \%$ liggen. Het gaat dus om de keuze: belegging of deelneming.

Indien het beleid van de deelnemer erop gericht is om met het betreffende kapitaalbelang een duurzame band te scheppen, indien de deelnemer een eigen belang heeft bij het houden van het kapitaalbelang en derhalve de eigen bedrijfsuitoefening van de deelnemer kan worden gediend, kan de kwalificatie deelneming in aanmerking komen. Het feit dat geen invloed op de dagelijkse gang van zaken kan worden uitgeoefend, is niet van belang (Pakhoed 1977). Deze criteria blijken feitelijk ook uit het wetsontwerp aanpassing vierde EG-richtlijn. De essentialia voor alle deelnemingen zijn daarin: kapitaalbelang en duurzame verbinding ten dienste van eigen werkzaamheid.

Een kwalificatievraagstuk is ook de vraag of een participatie in een vennootschap onder firma of commanditaire vennootschap een deelneming is resp. kan zijn. Uit een arrest van de Hoge Raad blijkt dat er geen rechtsregel is die verhindert dat de deelnemingsbepalingen op belangen in comman- 
ditaire vennootschappen met één beherend vennoot worden toegepast. Hiermee is de gestelde vraag dus positief beantwoord. Dit verandert onder de komende wetgeving niet.

\section{ad $b$. Waarderingsuraagstuk}

Dit vraagstuk is van twee kanten te bezien. Indien vaststaat dat sprake is van een deelneming in materiële zin dan zijn de voor deelnemingen geldende waarderingsvoorschriften van toepassing. Zijn bepaalde kapitaalbelangen op grond van wetsfictie als deelneming aan te merken ( $\geqslant 25 \%)$, terwijl in werkelijkheid sprake is van een belegging, dan gelden de waarderingsvoorschriften voor beleggingen. De waarderingsvoorschriften vloeien voort uit de norm van art. 311 boek $2 \mathrm{BW}$. Voor beleggingen zal dit veelal de verkoopwaarde (beurswaarde) dan wel verkrijgingsprijs of lagere verkoopwaarde zijn. Voor deelnemingen zijn dit gewoonlijk: de intrinsieke waarde, de verkrijgingsprijs of lagere intrinsieke waarde. Uit de jurisprudentie blijkt hierover het volgende.

In de Pakhoedprocedure bleek een strategische deelneming gewaardeerd te worden tegen kostprijs of lagere intrinsieke waarde. Dit is volgens de $\mathrm{OK}$ in overeenstemming met artikel 311. In het onderhavige geval acht de OK de vermelding van de beurswaarde in de toelichting noodzakelijk voor het inzicht in de liquiditeit en solvabiliteit. In dezelfde procedure achtte de OK de waarderingsgrondslag voor de minderheidsdeelnemingen, te weten 'het eigen vermogen volgens de balans aan het einde van het jaar, in van toepassing zijnde gevallen verhoogd met het nog niet afgeschreven van de betaalde meerwaarde' eveneens in overeenstemming met art. 311. In de procedure Ogem blijkt dat de OK de waarderingsgrondslag verkrijgingsprijs met afschrijving van de daarin begrepen goodwill eveneens in overeenstemming acht met artikel 311. De grondslag waarbij een dergelijke goodwill ten laste van de voorziening bijzondere doeleinden wordt geacht, acht zij onjuist. Uit de gecasseerde uitspraak $\mathrm{KSH}$ blijkt dat de OK waardering tegen verkrijgingsprijs niet onjuist acht.

$\mathrm{Al}$ de door de OK gesanctioneerde grondslagen blijven ook in de komende wetgeving toegelaten. Bovendien wordt hieraan waardering volgens de equity-methode ${ }^{4}$ toegevoegd. Zowel in dit geval als bij waardering tegen intrinsieke waarde moeten tegenover de ingehouden winsten na de verwerving, welke in de waardering zijn begrepen, wettelijke reserves worden gevormd.

ad c. Informatieuraagstuk

Over deelnemingen dienen getrouwe inlichtingen te worden verstrekt zowel met betrekking tot de waarde op balansdatum als met betrekking tot de waardewijzigingen tijdens het verslagjaar (art. 318). Voor deelnemingen die niet tegen intrinsieke waarde worden gewaardeerd, betekent dit dat de intrinsieke waarde in de toelichting moet worden vermeld (KSH 1974/75). Soms kan ook een andere waarde in aanmerking komen, bijvoorbeeld de beurswaarde indien dit uit oogpunt van liquiditeit en solvabiliteit van belang is (Pakhoed 1977). Voor beleggingen die krachtens wetsfictie als 
deelneming worden aangemerkt, zal als waarde de verkoopwaarde in aanmerking komen.

Omtrent de waardewijzigingen tijdens het verslagjaar zij opgemerkt dat voor alle deelnemingen gezamenlijk de waardewijzigingen per soort wijziging moeten worden verstrekt (Douwe Egberts). Het inzicht dat de jaarrekening dient te geven kan wel meebrengen dat over individuele deelnemingen afzonderlijke inlichtingen worden verstrekt. Zo oordeelde de $\mathrm{OK}$ in de Ogemprocedure het noodzakelijk dat het verlies op een deelneming afzonderlijk moet worden verstrekt, omdat dit verlies, zowel in verhouding tot de boekwaarde van de niet-geconsolideerde deelnemingen als tot de nettowinst aanzienlijk is en in zeer korte tijd is geleden. Ook uit de Pakhoedprocedure blijkt de noodzaak om in bijzondere omstandigheden over individuele deelnemingen afzonderlijk mededeling te doen; in deze procedure overwoog de OK dat het verlies van de deelneming moet worden vermeld gezien de omvang van het verlies en de structurele overcapaciteit.

Het voorgaande blijft ook onder de nieuwe wet in hoofdzaak gelijkluidend, zij het dat niet gesteld kan worden dat als deelnemingen tegen verkrijgingsprijs worden gewaardeerd er een verplichting bestaat om in de toelichting de intrinsieke waarde en de wijzigingen daarin te vermelden, maar mogelijkerwijze vloeit dit voort uit de algemene bepaling omtrent het inzicht dat de jaarrekening dient te geven. Wel dienen in ieder geval wijzigingen in de omvang van de deelnemingen en waardecorrecties afzonderlijk te blijken.

Over meerderheidsdeelnemingen moet meer informatie worden verstrekt; gewoonlijk geschiedt dit door het opnemen van een geconsolideerde jaarrekening. Het opnemen van een geconsolideerde deelneming mag er niet toe leiden dat het mutatie-overzicht van de deelnemingen in de enkelvoudige jaarrekening wordt weggelaten. Voorts geldt dat de geconsolideerde jaarrekening moet voldoen aan de wettelijke eisen van titel 6 BW2 (Van Gelderarrest). Het daarin op te nemen mutatie-overzicht deelnemingen heeft betrekking op de niet-geconsolideerde deelnemingen. De geconsolideerde jaarrekening treedt niet in de plaats van de (enkelvoudige) jaarrekening, omdat de geconsolideerde jaarrekening deel uitmaakt van de (enkelvoudige) jaarrekening (Eggerdingarrest). Het is ook niet toegestaan om deze stukken gescheiden vast te stellen en goed te keuren (Vulcaansoordarrest).

\section{ad d. Consolidatietechniek}

In de geconsolideerde jaarrekening zijn de deelnemingen die voor consolidatie in aanmerking kwamen, gewoonlijk opgenomen volgens de integrale consolidatietechniek. Soms worden deelnemingen evenwel proportioneel geconsolideerd. Omtrent de toelaatbaarheid van deze techniek merkt de OK in de Ultramarcoprocedure op dat een dergelijk ongebruikelijk stelsel dat veelal het verlangde inzicht zal vertekenen, slechts in uitzonderlijke gevallen aanvaardbaar is. Als eis moet dan wel worden gesteld dat de deelnemende rechtspersoon een aanmerkelijke invloed op de leiding van de deelneming moet kunnen uitoefenen. 


\section{Voorzieningen}

Op grond van de wet dienen van de voorzieningen in elk geval afzonderlijk te worden vermeld de voorziening voor latente belastingen en de pensioenvoorzieningen. De overige voorzieningen dienen naar de aard van de risico's en verplichtingen te worden gesplitst. In de komende wetgeving verandert hierin weinig, zij het dat het toelaatbaar is om voorzieningen voor kostenegalisatiedoeleinden te treffen. Voorts verlangt de komende wetgeving dat de aard van de voorzieningen nauwkeurig wordt omschreven met aanduiding in hoeverre zij tevens als langlopend moeten worden beschouwd.

In de jurisprudentie is in verschillende arresten de problematiek van de voorzieningen aan de orde gekomen. De aan de orde gekomen problematiek voor zover samenhangend met latente belastingen blijft hier onbesproken. Uit de arresten van de OK en HR blijkt in ieder geval dat als samenvoeging van voorzieningen heeft plaatsgevonden de samenvoeging moet worden vermeld en dat in ieder geval de aard van de risico's en de verplichtingen moet blijken (Douwe Egberts). Ook oordeelde de OK dat de term voorziening alleen moet worden gebruikt in de zin die de wet eraan hecht. Waardeverschillen uit een bestendig toe te passen waarderingsregel vallen daarbuiten (gecasseerd arrest KSH). Voorts behoeft niet vermeld te worden dat als een voorziening niet nodig wordt geoordeeld, de vorming daarvan achterwege is gebleven (Ogemarrest).

Omtrent de afzonderlijke tot de overige voorzieningen behorende voorzieningen zij het volgende nog opgemerkt. In de procedure Van Gelder oordeelde de OK dat het feit, dat een deel van de afwaarderingen op de activa als gevolg van reorganisatie niet ten laste van de reorganisatievoorziening is gebracht, maar op de latente belastingvoorziening, niet onvermeld had mogen blijven. Omtrent het besluit geen voorziening wegens afvloeiingskosten te vormen, oordeelde de OK dat dit op verantwoorde gronden was genomen, omdat tegenover de te verwachten afvloeiingskosten besparingen in gelijke omvang worden verwacht (Ultramarco 1975). In de procedure Gero oordeelde de OK dat de reorganisatievoorziening niet nader gesplitst behoeft te worden omdat deze getroffen is wegens met elkaar verband houdende totale resterende reorganisatiekosten, waarbij ook een afsplitsing wegens afvloeiingskosten niet noodzakelijk is. In de procedure Ogem bleek de OK van oordeel dat als van de tegen de vennootschap ingediende claims een redelijke schatting mogelijk was en daartegen voorzieningen zijn getroffen, het verantwoorde inzicht niet vereist dat de som van alle claims in de toelichting wordt genoemd. In dezelfde procedure werd het gebruik om koersverschillen te verwerken via een voorziening bijzondere doeleinden als onaanvaardbaar afgewezen. In de Sijthoffprocedure werd het juist geacht om de als gevolg van de verbreking van een arbeidscontract voorziene schade reeds in aanmerking te nemen in het verslagjaar, zelfs al zou de schade later optreden, omdat de oorzaak in het betrokken verslagjaar ligt. 


\section{Segmentatie van omzet, kosten en resultaat}

Er kunnen sedert 1971 drie fasen worden onderscheiden namelijk de periode 1971-1976, 1977-1982 en 1983 en later. In de eerste periode gelden geen segmentatievoorschriften, in de tweede periode gelden alleen segmentatievoorschriften voor het resultaat naar produktgroep en in de derde periode gelden - op grond van de huidige tekst van het wetsontwerp alleen segmentatievoorschriften voor de omzet naar afzetgebied en naar bedrijfstak.

In de eerste periode is segmentatie op grond van de minimumvoorschriften niet verplicht, hetgeen niet wegneemt dat de doelbepaling van de jaarrekening daartoe wel zou kunnen leiden. Een vordering op die grond is door de OK niet gehonoreerd omdat hiertoe naar de voor 1974 geldende maatstaven geen plicht bestond (Douwe Egbertsprocedure). In een andere procedure oordeelde de $\mathrm{OK}$ dat het om onlosmakelijk verbonden activiteiten gaat, terwijl bovendien noch gesteld noch gebleken is dat deze activiteiten een relevant verschil in risico's of winstgevendheid hebben, zodat de vorderingen van eisers worden afgewezen (Eggerdingprocedure).

In de tweede periode geldt dat inzicht moet worden gegeven in de mate waarin onderscheidene produktgroepen tot het bedrijfsresultaat hebben bijgedragen. $\mathrm{Bij}$ nauwe verwantschap tussen produkten kan evenwel niet gesproken worden over verschillende produktgroepen in de zin van de wet (Geroprocedure). Omtrent de wijze waarop het inzicht moet worden verstrekt, overweegt de $\mathrm{OK}$ in de procedure inzake de jaarrekening van Ultramarco dat de parlementaire wetsgeschiedenis geen duidelijk antwoord verschaft op de vraag op welke wijze inzicht in de resultaten moet worden gegeven, dat in de literatuur verschil van opvatting bestaat en dat in de praktijk nog geen vaste gedragsregel is ontstaan. In de Ogemprocedure oordeelde de OK dat de wettelijke voorschriften niet verplichten om resultaten te splitsen en toe te lichten naar bepaalde werken. Ook een splitsing van de 'overige bedrijfskosten' werd afgewezen, omdat een dergelijke splitsing niet voortvloeit uit de voor de betrokken bedrijfstak aanvaardbare maatstaven, terwijl ook het inzicht dat de jaarrekening dient te geven, daartoe niet leidt. In dezelfde zin oordeelde de OK in de Geroprocedure.

De derde periode breekt binnenkort aan. In hoeverre de jurisprudentie omtrent de segmentatie van het bedrijfsresultaat nog van betekenis blijft, hangt af van de parlementaire behandeling van het wetsontwerp aanpassing vierde EG-richtlijn. Niet ondenkbaar is dat alsnog een voorschrift, inhoudende een verplichting tot de segmentatie van het bedrijfsresultaat, in de nieuwe wet wordt opgenomen. Het wetsontwerp maakt terzake van de omzetsegmentatie wel duidelijk dat een verbale weergave van de segmentatie onvoldoende is.

\section{Afsluitende opmerkingen}

Uit het voorgaande is gebleken dat de $\mathrm{OK}$ in een aantal opzichten helderheid over de uitleg van de jaarrekeningvoorschriften van titel 6 BW2 heeft verschaft. De uitleg van de OK en de zienswijze van het Tripartiete overleg (TO) ontlopen elkaar weinig. Dit is ook niet te verwonderen: 
- Het uitgangspunt voor de OK en voor het TO is gelijk: titel 6 BW2.

- De OK betrekt in haar oordeelsvorming gezaghebbende literatuur, waarwonder de Richtlijnen van het TO.

- Het TO betrekt in zijn Richtlijnen mede de uitspraken van de OK.

Er ontstaat derhalve een proces van wederzijdse beïnvloeding, zij het dat een uiteenlopen van opvattingen daardoor niet wordt voorkomen. In het verleden kwam dit overigens niet of nauwelijks voor. Op dit moment zijn evenwel meer verwijderingen te constateren. Als voorbeelden noem ik:

\section{- deelnemingen}

Het TO gaat in beginsel uit van waardering tegen intrinsieke waarde, de $\mathrm{OK}$ acht evenwel andere waarderingsgrondslagen toelaatbaar. Het wetsontwerp aanpassing vierde EG-richtlijn sluit meer aan op de OK dan op het $\mathrm{TO}$.

\section{- voorraadwaardering}

Het TO acht waardering volgens lifo niet juist. Het wetsontwerp aanpassing vierde EG-richtlijn acht het lifo-systeem toelaatbaar. Naar verwachting zal de OK zich ook daarop richten.

Het TO gaat in beginsel van waardering tegen integrale kosten uit. De OK, evenals het wetsontwerp aanpassing vierde EG-richtlijn acht waardering beneden integrale kostprijs toelaatbaar (met bepaalde voorwaarden).

\section{- stelselwijzigingen}

De OK acht herrekening aan het begin van het jaar noodzakelijk en verlangt dat de invloed op het eigen vermogen per begin van het jaar aan het eigen vermogen wordt toegevoegd. Het TO acht in het algemeen toevoeging aan het resultaat noodzakelijk, tenzij het gaat om overgang van historische kosten naar actuele waarde.

Het resultaat van deze afwijkingen is ongewenste onduidelijkheid. Het ligt voor de hand aan de uitleg van de OK meer gewicht toe te kennen dan aan die van het TO. Hier staat tegenover dat het TO minder ad hoc gericht te werk gaat en mede daardoor als gevolg van een zekere voortrekkersrol kan bijsturen tot een betere verslaggeving.

$\underline{\text { Noten }}$

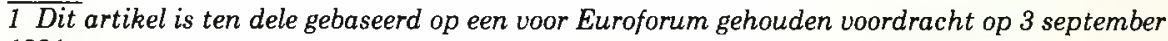
1981 .

2 Onder het wetsontwerp aanpassing vierde EG-richtlijn is het niet langer toegestaan om gecalculeerde rente over het eigen vermogen in de waardering van activa te betrekken.

3 Tegen dit punt is cassatie ingesteld; de Hoge Raad is aan een beoordeling niet toegekomen.

De Procureur-Generaal concludeerde voor wat betreft dit punt tot vernietiging van het arrest.

4 Waardering volgens verkrijgingsprijs verhoogd met winstinhoudingen bij de deelnemingen na verkrijging. 